\title{
Educação intercultural em religião de matriz africana na Amazônia: contribuições para uma Pedagogia Decolonial
}

\author{
João Colares da Mota Neto*
}

\begin{abstract}
Resumo
O artigo pretende refletir sobre as relações entre o pensamento decolonial e o campo da educação, tomando como base uma etnografia das práticas educativas interculturais desenvolvidas no cotidiano de uma religião de matriz africana na Amazônia, o Tambor de Mina. Os dados deste estudo foram obtidos por meio de uma pesquisa qualitativa, do tipo estudo de caso etnográfico, no qual se realizou observação participante das práticas sociais, religiosas e educacionais do terreiro, entrevistas semiestruturadas com membros da casa, entrevistas etnográficas com entidades espirituais incorporadas em seus adeptos, descrição densa e levantamento de traços da história de vida dos sujeitos. Espera-se, a um só tempo, contribuir para o debate epistemológico centrado no cruzamento entre decolonialidade e educação, bem como discutir, a partir de elementos presentes na prática investigada, a possibilidade de construção de uma pedagogia decolonial na Amazônia que, dentre outros contributos, promova a tolerância na diversidade cultural e religiosa.

Palavras-chave: Pedagogia decolonial; Educação; Tambor de Mina; Interculturalidade; Amazônia.
\end{abstract}

\section{Intercultural education in religion of African origin in Amazon: contributions to a Decolonial Pedagogy}

\begin{abstract}
The article aims to reflect on relations between the decolonial thought and the education, based on an ethnography of intercultural education developed in the daily life of a religion of African origin in Amazon, the Tambor de Mina. Data from this study were obtained through a qualitative research, of an ethnographic case study type, with participant observation of social, religious and educational practices of the religion, semi-structured interviews with members of the house, ethnographic interviews with spiritual entities incorporated in its followers, dense description and life story of the subjects. It is expected, at the same time, contributing to the epistemological debate centered at the intersection between decoloniality and education, as well as to discuss, from elements present in the investigated practice, the possibility of building a decolonial pedagogy in the Amazon which, among other contributions, promote the tolerance in the cultural and religious diversity.

Keywords: Decolonial Pedagogy; Education; Tambor de Mina; Interculturality; Amazon.
\end{abstract}

\section{Introdução}

O campo da educação, cada vez mais teorizado em seus cruzamentos com práticas e processos culturais, raciais, étnicos e de gênero, tem sido também problematizado, ainda que insuficientemente, por teorias e discursos que questionam o legado e o impacto do colonialismo, seja no âmbito formal das instituições de ensino, das políticas, do currículo, da didática, seja no contexto de práticas educacionais não formais, considerandose a educação como uma teia ampla e complexa de relações de saber-fazer-poder, que estrutura simbólica e materialmente a realidade, por meio dos valores, dos conhecimentos, das mentalidades e das práticas que disseminam, produzem e reproduzem.

Neste contexto, um conjunto crescente de autores tem elaborado críticas contumazes à reprodução do colonialismo ou de relações neocoloniais por meio da educação, desnudando concepções tradicionalistas ligadas a modelos

\footnotetext{
* Endereço eletrônico: joaocolares@ hotmail.com
}

societários conservadores; o racismo e o patriarcado como estruturas de poder colonial ensinadas de geração a geração; as relações entre a educação e os interesses do imperialismo e do capital; o uso de metodologias e estratégias formativas "bancárias", que silenciam as classes populares e favorecem a invasão cultural, entre outras questões.

Por outro lado, dialeticamente, a educação precisa ser vista não apenas como campo de reprodução de estruturas de dominação colonial, mas também como um espaço de resistências, especialmente em se tratando de educação na América Latina, continente que possui uma longa e densa história de lutas contra o colonialismo e a colonialidade, assim como contra o capitalismo, o racismo, o patriarcado e outros processos de exclusão e discriminação social.

Neste cenário, trazemos para discussão o chamado pensamento decolonial, como um campo epistêmico de problematização da modernidade/colonialidade, que em nosso 
entendimento apresenta fecundas possibilidades de crítica à colonialidade na educação, assim como caminhos para pensar a subversão destes padrões de poder colonial. Em particular, neste texto relacionamos o pensamento decolonial e a educação tomando como base uma etnografia realizada sobre as práticas educativas interculturais de uma religião de matriz africana na Amazônia, o Tambor de Mina.

O corpus deste trabalho provém de uma pesquisa de campo já concluída, resultado de nossa dissertação de mestrado defendida no Programa de Pós-Graduação em Educação da Universidade do Estado do Pará - UEPA, intitulada A Educação no Cotidiano do Terreiro: Saberes e Práticas Culturais do Tambor de Mina na Amazônia (MOTA NETO, 2008). A pesquisa foi realizada entre os anos de 2006 e 2008, com abordagem qualitativa, do tipo estudo de caso etnográfico (ANDRÉ, 2005), no qual realizamos observação participante sistemática e intensiva das práticas sociais, religiosas e educacionais do terreiro, entrevistas semiestruturadas com membros da casa, entrevistas etnográficas com entidades espirituais incorporadas em seus adeptos, descrição densa e levantamento de traços da história de vida dos sujeitos. O locus do estudo foi a Casa de Mina Estrela do Oriente, localizada no distrito de Benfica, no município de Benevides, Estado do Pará, pertencente à Mesorregião Metropolitana de Belém e à Microrregião Belém, na Zona Fisiográfica Bragantina.

Não obstante alguns dos dados empíricos desta investigação já terem sido socializados em outras publicações, o aspecto inovador deste ensaio é refletir sobre a educação intercultural do Tambor de Mina à luz do pensamento decolonial, buscando, a um só tempo, contribuir para o debate epistemológico centrado no cruzamento entre decolonialidade e educação, bem como discutir, a partir de elementos presentes nesta prática, a possibilidade de construção de uma pedagogia decolonial na Amazônia que, dentre outros contributos, promova a tolerância na diversidade cultural e religiosa.

Além desta introdução, o texto está organizado em outras três partes: inicialmente sintetizamos o significado de decolonialidade e de pensamento decolonial, em diálogo com autores do Programa de Investigação da Modernidade/Colonialidade Latino-Americano; em seguida, apresentamos dados sobre a educação intercultural e a ecologia de saberes do Tambor de Mina; por fim, à guisa de conclusão, refletimos sobre a necessidade de uma pedagogia decolonial na Amazônia, que reinvente modalidades de luta e insurreição contra o colonialismo e a colonialidade ainda vigentes, estimulando, em contrapartida, a construção de um projeto de sociedade democrática, inclusiva, autônoma, fundada no respeito às diferenças.

\section{O giro decolonial na América Latina}

O conceito de "decolonialidade", em suas derivações (pensamento, giro, inflexão decoloniais), tem sido desenvolvido por um conjunto de autores organizados em torno do Programa de Investigação da Modernidade/Colonialidade Latino-Americano, ou simplesmente, Rede Modernidade/Colonialidade, que reúne nomes como Enrique Dussel, Walter Mignolo, Aníbal Quijano, Catherine Walsh, Ramón Grosfoguel, Santiago Castro-Gómez, Edgardo Lander, Arturo Escobar, Nelson Maldonado-Torres, entre outros.

Em que pese a existência de diferenças intelectuais na rede modernidade/colonialidade, concordamos com Restrepo e Rojas (2010) quando identificam seis características fundamentais que constituem o projeto que defendem: 1) a distinção entre colonialismo e colonialidade; 2) a colonialidade como o "lado obscuro" da modernidade; 3) a problematização dos discursos euro-centrados e intramodernos da modernidade; 4) o pensamento em termos de um sistema mundializado de poder; 5) a rejeição de que seja um novo paradigma, apresentando-se como um paradigma outro; 6) a aspiração de que uma inflexão decolonial possa consolidar um projeto decolonial.

Quanto à diferença entre os conceitos de colonialismo e colonialidade, cabe esclarecer que o primeiro termo refere-se ao processo e ao aparato de domínio político e militar que se emprega para garantir a exploração do trabalho e das riquezas das colônias em benefício do colonizador, ao passo que a colonialidade é um fenômeno histórico mais complexo, que se estende ao presente e designa um padrão de poder que opera através da naturalização de hierarquias territoriais, raciais, culturais e epistêmicas, possibilitando a reprodução de relações de dominação (RESTREPO; ROJAS, 2010).

A respeito do par modernidade/colonialidade presente na escritura destes autores, deve-se à ênfase que querem dar à ideia de que a colonialidade é constitutiva e não derivativa da modernidade, que a colonialidade é o "lado obscuro" da modernidade, como gostam de afirmar, que o conceito emancipador 
hegemonicamente contido na ideia de modernidade é um mito porque não revela que ela só foi possível graças à opressão colonial que impôs aos povos conquistados da América Latina e de outros continentes subalternizados. Daí que as instituições e os processos sociais atrelados ao fenômeno histórico da modernidade passam a ser questionados por estes autores por suas inter-relações (diretas ou indiretas, manifestadas ou ocultadas) na constituição da exclusão social, do racismo, da negação de direitos e de modos de ser.

Com efeito, para Mignolo (2007), a modernidade é uma hidra de três cabeças, que simbolizam, cada qual: i) a retórica salvacionista, desenvolvimentista e a promessa do progresso, esta que é a única face visível da modernidade; ii) a colonialidade, que é um padrão de poder que permaneceu mesmo após o fim da situação colonial e que entre suas consequências estão o racismo, a desigualdade, a fome e o machismo, formas de opressão que costumam estar deslocadas do imaginário hegemônico sobre a ideia de modernidade; iii) a decolonialidade, que é uma energia de descontentamento, de desconfiança, de desprendimento mobilizada por aqueles que reagem ante a violência imperial.

Decolonialidade, na esteira destes autores, designa o questionamento radical e a busca de superação das mais distintas formas de opressão perpetradas contra as classes e os grupos subalternos pelo conjunto de agentes, relações e mecanismos de controle, discriminação e negação da modernidade/colonialidade. De outra forma, decolonialidade refere-se ao esforço por "transgredir, deslocar e incidir na negação ontológica, epistêmica e cosmogônico-espiritual que foi - e é - estratégia, fim e resultado do poder da colonialidade", de acordo com Catherine Walsh (2009, p. 27), o que significa, nas palavras de Walter Mignolo (2007, p. 27), que a decolonialidade é uma "energia que no se deja manejar por la lógica de la colonialidad, no si cree los cuentos de hadas de la retórica de la modernidad".

Trata-se de uma concepção, portanto, marcada por uma busca persistente pela autonomia, o que só pode ser entendido se tivermos em conta que a decolonialidade tem sido elaborada a partir das ruínas, das feridas, das fendas provocadas pela situação colonial. Desse modo, é a partir da dor existencial, da negação de direitos (incluindo os mais elementares, como o direito à vida), da submissão de corpos e formas de pensamento, da interdição a uma educação autônoma que nasce a concepção decolonial.
Sendo esta sua origem, a concepção decolonial, como não poderia deixar de ser, revela sua primeira face como constituída pela negação à negação. Ela é, assim, anticolonial, não eurocêntrica, antirracista, antipatriarcal, anticapitalista, em seus devidos desdobramentos, e assume um enfrentamento crítico contra toda e qualquer forma de exclusão que tenha origem na situação colonial e nas suas consequências históricas. Da negação à negação tem surgido, assim, em sua face positiva, distintas propostas de reinvenção da existência social, do pensamento, da educação, da cultura, da ciência, da filosofia.

É exatamente isso que tem sido chamado de giro decolonial. Nas palavras de Maldonado-Torres:

(...) en primer lugar, un cambio de perspectiva y actitud que se encuentra en las prácticas y formas de conocimiento de sujetos colonizados, desde los inicios mismos de la colonización, y, en segundo lugar, un proyecto de transformación sistemática y global de las presuposiciones e implicaciones de modernidad, asumido por una variedad de sujetos en diálogo" (MALDONADO-TORRES, 2007, p.160).

Para Maldonado-Torres (2008), o conceito de giro decolonial, em sua expressão mais básica, põe no centro do debate a questão da colonização como componente constitutivo da modernidade, e a descolonização como uma quantidade indefinida de estratégias e formas de contestação com vistas a uma mudança radical nas formas hegemônicas atuais de poder, ser e conhecer.

De outra maneira, Mignolo (2007, p. 26) compreende o giro decolonial como "la conceptualización misma de la colonialidad como constitutiva de la modernidad", o que significa dizer que a perspectiva decolonial procura revelar o terror, a morte, a discriminação e o epistemicídio escondidos por detrás da retórica salvacionista da modernidade.

É a partir dessa ideia que Walter Mignolo (2007) sustenta que o pensamento decolonial emergiu quando da fundação mesma da modernidade/colonialidade, como sua contrapartida, fato ocorrido nas Américas com o pensamento indígena e o afro-caribenho, nos séculos XVI e XVII, considerado pelo autor como o primeiro momento da genealogia deste pensamento.

$\mathrm{O}$ segundo momento, conforme Mignolo, ocorreu na Ásia e na África, nos séculos XVIII e 
XIX, não relacionado com o pensamento decolonial nas Américas, mas como a resposta da reorganização da modernidade/colonialidade do império britânico e do colonialismo francês.

O terceiro momento, em sua análise, teve lugar na interseção dos movimentos de descolonização na África e Ásia, concorrentes com a Guerra Fria e a liderança ascendente dos Estados Unidos e da União Soviética. E é após a Guerra Fria que o pensamento decolonial começa a traçar sua própria genealogia, conforme Mignolo (2007).

Observamos, assim, que a genealogia do pensamento decolonial proposta por Mignolo estabelece que as produções intelectuais dos integrantes da rede modernidade/colonialidade são herdeiras diretas dos pensamentos de resistência indígena e afro-caribenho que se desenvolveram na América Latina. Isto implica considerar que desde a implantação da matriz colonial de poder tem havido uma fecunda prática epistêmica decolonial, ainda que uma reflexão mais sistemática sobre o giro decolonial seja recente, por volta dos anos 90 do século XX em diante, quando começa a se articular os principais conceitos que desembocarão no programa de investigação da modernidade/colonialidade latino-americano.

Neste mesmo sentido, Maldonado-Torres (2008) entende que o giro decolonial como uma mudança de atitude que confronta o colonialismo em alguma de suas formas é talvez tão velho como o mundo colonial mesmo, e que esta atitude contestatória tem inspirado distintos projetos decoloniais em vários momentos da modernidade. No entanto, assim como Mignolo, Maldonado-Torres afirma que é somente no século XX que estes projetos decoloniais começaram a se encontrar e chegaram a criar uma consciência global sobre a relevância do projeto inacabado da descolonização.

(...) el giro des-colonial se trata pues de una revolución en la forma en que variados sujetos colonizados percibían su realidad y sus posibilidades tras la caída de Europa en la Segunda Guerra Mundial. Ya las bases del giro des-colonial estaban planteadas de antemano en el trabajo de intelectuales racializados, en tradiciones orales, en historias, canciones, etc., pero, gracias a eventos históricos particulares, se globaliza a mitad del siglo XX. De ahí en adelante puede decirse que se planteó un giro, ya no sólo al nivel de la actitud de sujetos o de comunidades específicas, sino al nivel del pensamiento mundial

(MALDONADO-

TORRES, 2008, p. 70).

O pensamento decolonial, desse modo, pode ser entendido como a dimensão gnosiológica e epistemológica contida na ideia de decolonialidade, ou seja, como um conjunto de práticas epistêmicas de reconhecimento da opressão, mas, sobretudo, como um paradigma outro de compreensão do mundo, interessado em revelar, e não esconder, as contradições geradas pela modernidade/colonialidade, em diálogo crítico com as teorias europeias, mas elaborado, fundamentalmente, a partir de uma perspectiva não eurocêntrica de mundo, atenta às realidades vividas pelas populações periféricas e aos seus conhecimentos, às suas culturas e às suas estratégias de luta.

De acordo com Mignolo (2007), é preciso traçar uma genealogia do pensamento decolonial, no sentido de recuperar, na história das populações e culturas colonizadas, estas práticas epistêmicas decoloniais, ou seja, conhecimentos que surgiram como contrapartida e resistência à matriz colonial de poder, desde o início do processo colonizador, mas que foram soterrados pelo eurocentrismo epistemológico. Segundo este autor, a genealogia do pensamento decolonial não se limita a indivíduos, a intelectuais, mas também considera movimentos sociais e instituições que gestam em seu interior a decolonialidade nas esferas do saber, do existir e do poder. É assim que ele inclui nesta genealogia nomes como os de Mahatma Gandhi, W. E. B. Dubois, Juan Carlos Mariátegui, Amílcar Cabral, Aimé Césaire, Frantz Fanon, Fausto Reinaga, Vine Deloria Jr., Rigoberta Menchú, Gloria Anzaldúa, além do Movimento Sem-Terra brasileiro, os zapatistas em Chiapas, os movimentos indígenas e afros na Bolívia, no Equador e na Colômbia, o Fórum Social Mundial e o Fórum Social das Américas (MIGNOLO, 2007). Defendemos a inclusão, nesta relação necessariamente incompleta, dos nomes de Paulo Freire e Orlando Fals Borda, que contribuíram significativamente, a partir dos movimentos da educação popular e das ciências sociais críticas, para a constituição de uma concepção decolonial na América Latina ${ }^{1}$.

Este conjunto de intelectuais, ao reconhecer que o fim do colonialismo não significou a supressão das relações desiguais de poder originadas na situação colonial, que foram ressignificadas no capitalismo e na colonialidade global, defendem que devemos passar por uma segunda descolonização, 
que complete a primeira, e que estenda a emancipação para um nível mais amplo que o meramente jurídico-político, incluindo a economia, a ciência, a igualdade racial e de gênero, a educação e a criação de novas formas de sociabilidade e de interação com as pessoas, as culturas e a natureza. É a esta segunda descolonização que se refere, precisamente, o conceito de decolonialidade ${ }^{2}$. $\mathrm{Na}$ explicação de Castro-Gómez e Grosfoguel (2007, p. 17):

La primera descolonialización (iniciada en el siglo XIX por las colonias españolas $y$ seguida en el XX por las colonias inglesas $y$ francesas) fue incompleta, ya que se limitó a la independencia jurídico-política de las periferias. En cambio, la segunda descolonialización - a la cual nosotros aludimos con la categoría decolonialidadtendrá que dirigirse a la heterarquía de las múltiples relaciones raciales, étnicas, sexuales, epistémicas, económicas y de género que la primera descolonialización dejó intactas. Como resultado, el mundo de comienzos del siglo XXI necesita una decolonialidad que complemente la descolonización llevada a cabo en los siglos XIX y XX. Al contrario de esa descolonialización, la decolonialidad es un proceso de resignificación a largo plazo, que no se puede reducir a un acontecimiento jurídico-político.

No excerto acima, Castro-Gómez e Grosfoguel utilizam uma palavra comumente presente na literatura decolonial, a heterarquia, para dar conta da realidade complexa que marca tanto a colonialidade, quanto a decolonialidade. Buscando ser um "paradigma Outro", a perspectiva decolonial procura superar as abordagens reducionistas e verticalizadas tão fortemente presentes nas ciências modernas e, em particular, nas ciências sociais. Já não interessa a eles dar primazia ou ao sujeito, ou às estruturas; ao desejo, ou ao poder; à economia, ou à cultura; à classe social, ou à raça e ao gênero; à sociedade, ou à natureza. Interessa, ao contrário, entender como o colonialismo e a colonialidade afetaram todos estes níveis da vida social e quais são suas inter-relações reais e potenciais.

É neste sentido que Castro-Gómez e Grosfoguel (2007) afirmam que a rede modernidade/colonialidade procura por uma linguagem que expresse a complexidade da vida social, e já que as ciências humanas e sociais, bem como as filosofias modernas, estão largamente comprometidas com uma visão dicotômica e fechada de mundo - que Boaventura de Sousa Santos (2002) chamaria de razão indolente -, os intelectuais da rede têm procurado essa linguagem fora dos paradigmas acadêmicos tradicionais, em diálogo tanto com formas não ocidentais de conhecimento, quanto com novas teorias da complexidade.

Portanto, o diálogo com formas não ocidentais de conhecimento, como a sabedoria indígena e africana, por exemplo, é impulsionado tendo em vista não uma etnografia das diferenças, mas uma aprendizagem mútua que conduza a uma outra maneira de pensar o mundo, uma epistemologia de fronteira, elaborada a partir da interlocução crítica entre modos distintos de conceber o real.

É a partir desta perspectiva que buscaremos refletir, a seguir, sobre as práticas educacionais do Tambor de Mina.

\section{A educação no Tambor de Mina: interculturalidade e ecologia de saberes}

O Tambor de Mina, também chamado simplesmente de Mina, é uma religião nascida no Nordeste brasileiro, mais precisamente no Maranhão, e posteriormente recriada na Amazônia, onde adquiriu traços particulares da cultura e sociedade locais. Segundo Ferretti (2000), é também a denominação mais difundida das religiões afrobrasileiras no Maranhão e na Amazônia, sendo que a palavra "tambor" deriva da importância do instrumento homônimo nos rituais de culto e "mina" dos negros da Costa da Mina, nome dado aos escravos procedentes da costa situada a leste do Castelo de São Jorge de Mina, na atual República do Gana, trazidos da região das Repúblicas do Togo, Benin e Nigéria e que eram conhecidos como negros mina-jejes e mina-nagôs ${ }^{3}$.

O processo histórico de formação do Tambor de Mina, a exemplo de outras denominações das religiões afro-brasileiras, constitui-se a partir de uma confluência de tradições culturais, religiosas, étnicas e linguísticas, o que ajuda a entender, em parte, a característica intercultural das práticas educativas que se desenvolvem no espaço do terreiro pesquisado.

Além da combinação de tradições de diversas nações africanas, das quais a jeje (originária dos negros escravos vindos de Daomé, atual República Popular do Benin) e a nagô (do povo sudanês, habitante da região de Ioruba, na Nigéria) 
não são as únicas, mas são as mais expressivas, o terreiro pesquisado incorpora elementos do Catolicismo, da Umbanda, do Candomblé, do Terecồ $^{4}$, da Pajelança, do Kardecismo, uma característica sincrética já exaustivamente analisada na literatura antropológica sobre as religiões de matriz africana.

Neste sentido, Roberto Motta (1993) comenta que Arthur Ramos, célebre estudioso das religiões afro-brasileiras, distinguiu sete tipos de sincretismo, desde o puramente africano, denominado Fon-Iorubá (referente à interação jejenagô) até o complexo modelo Fon-IorubáMulçumano-Banto-Ameríndio-Espírita-Católico-

Teosofismo, modelo este que se aproxima da casa de culto investigada.

Quando falamos especificamente dos cultos afro-brasileiros do Pará, incluindo-se a Casa de Mina Estrela do Oriente, os elementos ameríndios transparecem com maior evidência tanto no conjunto de crenças, quanto nos ritos e nas práticas religiosas. A Mina, no contato com a pajelança, abre-se para entidades $^{5}$ pertencentes às matas e às águas amazônicas. Além disso, a existência de sessões de cura xamânica em determinados terreiros de Mina paraense, entre os quais o terreiro que estudamos, atesta o sincretismo afro-ameríndio próprio desse experimento religioso. Nos rituais, elementos de origem indígena manifestam-se, destacando-se a presença de objetos, como cigarro de tauari e cachaça; a cura por sucção e retirada de animais de corpos enfeitiçados; os banhos e remédios com ingredientes da fauna e flora amazônicas.

Referente à "tradução" amazônica dos cultos religiosos vindos do Maranhão, Carneiro (1959, p. 16) afirma que na Amazônia se encontra, "além dos cigarros de tauari e das espadas, figuras de pajelança, como os mestres Carlos, Marajó e Paroá, a palmeira Jarina transformada em divindade alegre e estouvada e os voduns e orixás trazidos do Maranhão". Vicente Salles (1969) denomina de sincretismo afroameríndio para a coexistência da pajelança e da magia africana no universo religioso do Pará.

Este sincretismo afro-ameríndio, no plano do panteão dos cultos do Pará, foi alvo de investigações de Figueiredo (1994, p. 79), que afirma que encontramos nesses cultos ofídios, cetáceos, quelônios, crocodíleos, psitacídeos, electroforídeos e outras espécies da fauna amazônica, que habitam as florestas e o fundo dos rios, ao lado de índios, caboclos, príncipes e marinheiros integrados ao fabulário popular da Amazônia e que povoam as "encantarias".
Não sendo nosso objetivo aprofundar a descrição histórica e antropológica do Tambor de Mina, mas tão somente destacar o quadro complexo, plural e híbrido em que a religião tem desenvolvido suas práticas, afirmamos que o Tambor de Mina opera uma ecologia de saberes (SANTOS, 2006), na medida em que um conjunto vasto de conhecimentos de várias matrizes étnicas e culturais está presente na sua formação histórica, na ritualística, no panteão cultuado e nos processos educativos cotidianos de formação dos adeptos. Em função disso, analisamos que a educação do Tambor de Mina caracteriza-se como intercultural, conceito que pressupõe, conforme Santos e Meneses (2010, p. 10), "o reconhecimento recíproco e a disponibilidade para enriquecimento mútuo entre várias culturas que partilham um dado espaço cultural".

$\mathrm{Na}$ área da educação, a interculturalidade tem sido definida como:

(...) um enfoque que afeta a educação em todas as suas dimensões, favorecendo uma dinâmica de crítica e autocrítica, valorizando a interação e comunicação recíprocas, entre os diferentes sujeitos $e$ grupos culturais. [...] A interculturalidade orienta processos que têm por base o reconhecimento do direito à diferença e a luta contra todas as formas de discriminação $e$ desigualdade social. Tenta promover relações dialógicas e igualitárias entre pessoas e grupos que pertencem a universos culturais diferentes, trabalhando os conflitos inerentes a esta realidade (CANDAU; KOFF, 2006, p. 475).

(...) em nível das práticas educacionais, a perspectiva intercultural propõe novas estratégias de relação entre sujeitos e entre grupos diferentes. Busca promover a construção de identidades sociais $e$ o reconhecimento das diferenças culturais. Mas, ao mesmo tempo, procura sustentar a relação crítica e solidária entre elas (FLEURI, 2001, p. 49).

Dos conceitos destes autores, depreendemos que uma educação pode ser chamada de intercultural quando: a) possibilita o diálogo entre sujeitos e culturas distintas; b) enfatiza a comunicação mais que a transmissão; c) provoca a crítica em torno das desigualdades e discriminações relacionadas a fatores culturais e identitários; d) afirma as 
identidades socioculturais de grupos historicamente excluídos.

No terreiro pesquisado, as práticas educacionais se aproximam desta caracterização, na medida em que promovem:

a) a aprendizagem do conjunto religioso sincrético, ensinando formas de interação entre divindades, linguagens e rituais;

b) o compartilhamento de saberes oriundos de diversas fontes históricas, geográficas e étnicas, particularmente através do aconselhamento, prática educativa em que os saberes ancestrais dos encantados e da religião são socializados na comunidade;

c) o diálogo e o respeito ao ser humano, independentemente de suas idiossincrasias culturais, posto que a base moral da religião está ancorada na prática da caridade e nos valores de reciprocidade, respeito, cuidado e humildade;

d) a aprendizagem via experiência religiosa direta, ou uma educação pela prática ritual, reduzindo-se o papel educativo da transmissão, logo, da hierarquia entre os que sabem e os que não sabem;

e) o respeito a indivíduos pertencentes a grupos social e culturalmente excluídos, como as mulheres, os idosos, as crianças, os índios, os negros, os mulçumanos, os homossexuais, não só aceitos na religião, como representados por entidades ou divindades;

f) a aprendizagem não somente dos médiuns, mas também dos encantados, entendidos como seres da natureza em processo contínuo de formação, razão pela qual desenvolvem sua linguagem e espiritualidade na relação com os outros.

Os saberes que circulam no terreiro, neste contexto de educação intercultural, são de diferentes matizes: saberes da prática religiosa e ritual, ensinamentos morais, saberes ancestrais dos encantados, narrativas míticas, fundamentos religiosos (preservados pelo uso do segredo) e todo tipo de fórmulas, receitas, gramáticas e códigos provenientes das tradições históricas do Tambor de Mina na Amazônia.

No Tambor de Mina, os saberes da tradição são socializados de uma geração a outra nas relações de comunicação direta, nas conversas e no convívio diário, utilizando-se de narrativas orais que veiculam as memórias coletivas da religião e do povo de santo. Nessa cultura educativa, a ideia de experiência é fundamental, uma vez que a sabedoria é adquirida na prática religiosa cotidiana, ao sabor do tempo.

Neste sentido, os saberes ancestrais do Tambor de Mina, guardados pelos mais experientes e frequentemente pelos mais velhos, nos exige que seja valorizada a figura destes guardiões de tradições, pois são os responsáveis por manter a vitalidade da memória coletiva, contar os mitos de origem, venerar os antepassados, inclusive recuperando sabedorias e práticas que foram soterradas pelo epistemicídio provocado pela modernidade/colonialidade.

Com Goff (1992, p. 429), a respeito das sociedades sem escrita, poderíamos chamar estes sujeitos de homens-memória, que são verdadeiros especialistas da memória, “'genealogistas', guardiões dos códices reais, historiadores da corte, "tradicionalistas"', com o importante papel de manter a coesão do grupo. Consideramos que os sacerdotes da Mina assumem o papel de homens-memória, cabendo-lhes a tarefa de agentes educativos na tradução e socialização dos códigos culturais provenientes da tradição.

Em função do Tambor de Mina ser uma religião profundamente sincrética, constituída a partir da convergência de diferentes tradições (ibéricas, ameríndias, africanas), os saberes dessa religião são marcados por traços de mestiçagem cultural, no plano do panteão, da ritualística, da doutrina e da linguagem. Os guias espirituais e os sacerdotes, como propulsores desses processos de mestiçagem cultural, podem também ser caracterizados como mediadores culturais (passeurs culturels), termo cunhado pelo historiador Serge Gruzinski (2001, 2003), para ser usado como instrumento analítico dos processos de intercâmbio cultural.

O pai de santo, ao ser considerado o guardião das tradições da Mina, assume a liderança não somente espiritual, mas educacional no terreiro, responsável pela socialização dos saberes das gerações anteriores, estabelecendo uma mediação entre diferentes culturas. Os encantados e as divindades, em suas narrativas mitológicas, estabelecem complexas e intensas ligações entre tempos e espaços históricos diversos. A África mitológica, a Europa e a Ásia de nobres e princesas, a América Latina da época escravocrata e o Brasil indígena e rural são cenários cantados, narrados e ensinados no cotidiano dos terreiros de Mina.

Dessa maneira, observamos nas manifestações de educação no terreiro que esses universos culturais se entrecruzam no cotidiano da casa, dimensionando a educação intercultural cujos argumentos estamos tentando desenvolver.

Para Tramonte (2004), sob o prisma da intercultura, as práticas das religiões afro-brasileiras apresentam-se como um campo híbrido de 
construção de identidades. Esse campo possibilita a criação e circulação de saberes interculturais, que são preservados na religião em decorrência da importante atuação dos sacerdotes e demais adeptos, os quais, por meio da oralidade, das narrativas mitológicas, do aconselhamento e dos trabalhos de desenvolvimento, socializam saberes e tradições registrados na memória coletiva do povo de santo.

Desse modo, os saberes da tradição fornecem elementos aos membros da comunidade do terreiro para a constituição de sua identidade cultural e religiosa, com seu modo próprio de ser, pensar e agir sobre o mundo. A memória não apenas registra os episódios do passado, mas ensina, por meio dos saberes da tradição, formas de agir e explicar o mundo atual. Os sacerdotes e os encantados são os principais responsáveis por resguardar tais saberes.

Além disso, esta educação, por rememorar sabedorias ancestrais, possibilita também a resistência e sobrevivência da cultura afro-brasileira, a despeito do racismo, da intolerância religiosa e da discriminação estrutural contra negros e classes populares em nosso país.

$\mathrm{Na}$ etnografia realizada, constatamos que a educação intercultural no terreiro realiza-se sob muitos formatos: na experiência diária, nos rituais, nas relações sociais, nas rodas de conversa, nos trabalhos de desenvolvimento mediúnico e em muitos outros espaços. Algumas das principais manifestações de educação observadas foram: educação moral e a prática do aconselhamento; a educação pela prática ritual; os trabalhos de desenvolvimento dos médiuns e a doutrinação dos encantados.

Em relação à primeira manifestação, concluímos que a socialização dos valores cultivados ao longo da história do Tambor de Mina constitui uma das mais importantes práticas de formação dessa religião, possibilitando que os seus adeptos compartilhem uma base moral ancorada na prática da caridade e nos valores da reciprocidade, respeito, cuidado e humildade. Os valores de respeito à natureza e ao ser humano e o tipo de relação dialógica construída pelos adeptos no cotidiano do terreiro levam-nos a identificar uma dimensão ética e ecológica das suas práticas educativas. Vimos que o diálogo está presente na educação do terreiro por meio de uma prática fundamental para o repasse dos saberes da tradição: a prática do aconselhamento, entendida como narrativa oral que conduz importantes saberes da religião: os valores, os fundamentos e a mitologia.

Quanto à educação pela prática ritual, trata- se de uma manifestação eminentemente experiencial de ensino-aprendizagem, realizada de modo pouco verbalizado, ao longo da experiência ritual de um adepto. Essa educação conduz os fiéis para a aprendizagem de movimentos, atitudes, dizeres, fórmulas que constituem a complexa ritualística do Tambor de Mina. Os rituais, nesse sentido, devem ser entendidos no contexto da ação simbólica, capazes de transmitir códigos culturais importantes na formação dos adeptos. Os rituais educam os indivíduos também para a construção de uma determinada performance religiosa, permitindo-lhes internalizar gestos e dizeres. É, fundamentalmente, por meio dessa manifestação de educação que os médiuns se preparam para o canto, o toque e a dança, configurando, assim, uma dimensão estética da educação.

Finalmente, quanto aos trabalhos de desenvolvimento, consistem na formação religiosa (ritual, doutrinária, espiritual) dos médiuns, ensinando-se, de uma maneira mais sistemática que as outras formas, o chamado "ABC da Mina": tradições, doutrinas, fundamentos, formas de execução ritual, valores culturais, entre outros saberes importantes para a formação de um médium. A despeito da formação mediúnica não ocorrer unicamente no terreiro, em função de os médiuns seguirem um itinerário formativo ao longo de sua vida, na Casa de Mina Estrela do Oriente realizam-se sessões de desenvolvimento e sessões astrais, especialmente dedicadas à educação dos médiuns, nos aspectos da incorporação, do comportamento, do desempenho ritual e da vidência.

\section{À guisa de conclusão: a necessidade de construção de uma Pedagogia Decolonial na Amazônia}

A Amazônia, com uma área que ultrapassa cinco milhões de $\mathrm{Km}^{2}$, o equivalente a $61 \%$ do território brasileiro, é uma região mundialmente conhecida por sua biodiversidade, ilustrada pela enorme quantidade de espécies animais e vegetais, distribuídas em ecossistemas florestais, terrestres e aquíferos. No entanto, frequentemente, é ignorada a expressiva sociodiversidade da Amazônia, que possui mais de 20 milhões de habitantes que compartilham um manancial milenar de culturas, saberes, imaginários, mitologias e manifestações religiosas e artísticas.

Esta negação da sociodiversidade amazônica está relacionada ao forte processo colonizador aqui vivido, centrado na exploração da mão de obra 
nativa; na destruição dos ecossistemas locais, estes que, para além de uma manifestação da natureza, estão em relação inquebrantável com as culturas ancestrais; na interdição do corpo do indígena, do negro, do camponês, do ribeirinho, do quilombola; na proibição das religiosidades e mitologias de grupos étnicos dominados; na reprodução de uma educação colonizadora que promoveu epistemicídio e violência simbólica contra as culturas nativas.

Este quadro histórico nos exige a construção de uma pedagogia que recupere estes saberes negados, que parta das memórias de resistência dos grupos subalternos amazônicos, que incorpore e valorize as diferenças étnicas, raciais, de gênero, religiosas oprimidas pela modernidade/colonialidade, que construa formas de pensar o mundo em diálogo com as sabedorias dos grupos originários amazônicos, que estimule formas de vida e sociabilidade que respeitem o equilíbrio sistêmico dos ecossistemas locais.

De outro modo, é preciso construir uma pedagogia que parta das práticas epistêmicas decoloniais dos grupos oprimidos de nossa região, práticas que têm sido construídas, como vimos no início deste texto, desde a Conquista, como sua resposta, como resistência, como contrapartida. Isso é, ainda no período colonial, os segmentos violentados empreenderam uma resistência não só política, mas também cultural, simbólica, educacional contra o colonialismo e a lógica da colonialidade, buscando preservar, evidentemente de maneira dinâmica e histórica, os núcleos centrais de sua ancestralidade, de sua cosmovisão.

Defendemos a ideia de que o Tambor de Mina, por meio de sua educação intercultural, contribuiu significativamente para a sobrevivência e atualização das práticas epistêmicas decoloniais de negros e indígenas no Brasil e na Amazônia, constituindo-se, portanto, como um importante aporte à construção de uma pedagogia decolonial em nossa região.

De acordo com Catherine Walsh (2009), as pedagogias decoloniais dialogam com os antecedentes crítico-políticos dos grupos subalternos ao partir de suas lutas e de sua práxis de orientação decolonial. São pedagogias que se esforçam por transgredir a negação do ser, do saber e do poder dos grupos colonizados. Para esta autora, as pedagogias decoloniais devem ser entendidas para além do sistema educativo, do ensino e da transmissão do saber, mas como "processo e prática sociopolíticos produtivos e transformadores assentados nas realidades, subjetividades, histórias e lutas das pessoas, vividas num mundo regido pela estrutura colonial" (WALSH, 2009, p. 26).

De outro modo, para Díaz (2010), uma pedagogia decolonial deve assumir uma compreensão crítica da história, reposicionar práticas educativas de caráter emancipatório e se descentrar da perspectiva epistêmica colonial, abrindo-se a outras abordagens que afetem não somente os conteúdos a serem ensinados, mas também suas metodologias e apostas didáticas.

No caso do Tambor de Mina, a educação praticada possibilita a sobrevivência, de geração a geração, dos valores civilizatórios africanos, que se hibridizaram, como vimos, com outras tradições culturais.

Neste sentido, cabe destacar, com Oliveira (2003), que na Diáspora africana o que vem para o Brasil não é a estrutura físico-espacial das instituições nativas africanas, mas os valores e princípios negro-africanos, denominados por este autor de aspectos civilizatórios. Diz que, ao mesmo tempo em que significou ruptura violenta com os valores civilizatórios africanos, a diáspora serviu para que esses valores se espalhassem mundo afora, não por proselitismo dos negros, mas pela imposição artificial de viverem em terras estrangeiras. E foi no seio da religião afro-brasileira - o autor refere-se particularmente ao Candomblé - que tais aspectos civilizatórios podem ser melhor percebidos.

Concordamos com o autor e afirmamos que a educação intercultural do Tambor de Mina reaviva valores civilizatórios como a circularidade, a oralidade, a corporeidade, a memória, a ancestralidade, a musicalidade, a solidariedade, a ecologia, a ética, integrando o saber à experiência, a mente ao corpo, a cultura à natureza, a diferença à igualdade, questões que nos parecem absolutamente fundamentais para $o$ fortalecimento de uma pedagogia decolonial na Amazônia que, dentre outros contributos, promova a tolerância na diversidade cultural e religiosa.

Importante também chamar a atenção para a forte marca intercultural na educação do Tambor de Mina, que, ao permitir uma confluência de tradições, com destaque para as culturas africanas e indígenas, dimensiona-se como uma ferramenta de resistência à colonialidade do saber promovida pela modernidade/colonialidade. Segundo Carlos Walter Porto-Gonçalves (2005), a colonialidade do saber nos revela, para além do legado de desigualdade e injustiça sociais profundos do colonialismo e do imperialismo, que "há um legado epistemológico do eurocentrismo que nos impede de compreender o 
mundo a partir do próprio mundo em que vivemos e das epistemes que lhes são próprias" (PORTOGONÇALVES, 2005, p. 10).

Urge, assim, utilizando terminologia de Boaventura de Sousa Santos e Maria Paula Meneses (2010), construir e dar visibilidade às Epistemologias do Sul, que, contrapondo-se à epistemologia dominante, ocidental, moderno/colonial, buscam reconhecer as formas de conhecimento de populações historicamente excluídas. Com este propósito, consideramos que estudar a educação no terreiro, seus saberes e suas práticas, contribui para dar visibilidade a lógicas, gramáticas, conhecimentos e experiências que têm sido desprezados não só pela ciência, de uma maneira geral, mas pela Pedagogia, especificamente.

É neste sentido que construir e fortalecer epistemologias do Sul a partir dos conhecimentos subalternizados pela modernidade/colonialidade, tais como os que temos identificado no Tambor de Mina, ajuda a romper com o autoritarismo da ciência dominante, engendrando formas de conhecimento mais plurais, democráticas, ecológicas e interculturais. Ajuda, também, a promover a tolerância com os diferentes e a construção de uma sociedade solidária e inclusiva, com espaço aberto para o diálogo intercultural e inter-religioso.

É o próprio Santos (2006) quem diz que perspectivas interculturais têm possibilitado o reconhecimento de uma diversidade de saberes alternativos à ciência moderna ou que com esta se articula em novas configurações de conhecimentos. Sabendo-se da dimensão intercultural das práticas educativas e religiosas do Tambor de Mina, consideramos que a legitimação de suas matrizes de conhecimento ajuda a construir as epistemologias do Sul a partir das quais surja uma Pedagogia cada vez mais aberta ao diálogo com o Outro, uma pedagogia, enfim, decolonial.

Mas, para além do aspecto epistemológico, a educação do Tambor de Mina, pelos valores que ensina (como o cuidado, a solidariedade, a humildade) e pelo acolhimento e respeito a grupos socialmente excluídos (como negros, homossexuais, indígenas, mulheres), configura-se como uma prática ética de respeito ao Outro e de valorização da alteridade negada.

A educação do Tambor de Mina, desse modo, contribui para a crítica da colonialidade do ser, que também engendra a modernidade/colonialidade, pela negação das corporalidades dos oprimidos, por sua profunda desumanização, pelo racismo e pelo patriarcado que inferiorizam negros, índios e mulheres. A colonialidade do ser, segundo Maldonado-Torres (2007), representa a negação do direito à existência e à liberdade dos grupos colonizados.

O giro decolonial, desse modo, articulado a um projeto pedagógico decolonial, é também um giro humanístico, ancorado, segundo Maldonado-Torres (2007), no reconhecimento de todo ser humano como membro real de uma espécie. Como isto não se dá fora das relações sociais, claro está que a construção deste novo humanismo implica na luta contra todas as formas de exploração levadas a efeito pelo sistema moderno/colonial, sobretudo o capitalismo, o patriarcado e o racismo.

Para finalizar, cabe destacar que o Tambor de Mina é apenas uma dentre muitas outras práticas epistêmicas decoloniais que, ao resistir à colonialidade, constituiu seu próprio modo de viver, pensar o mundo e entrar em comunhão com o cosmos e a natureza. É urgente que pesquisadores da educação se debrucem sobre as culturas ancestrais de indígenas, africanos, ribeirinhos, quilombolas e outros grupos ancestrais amazônicos com vistas a aprender e apreender elementos que apontem para relações sociais e formas de sociabilidade mais éticas e solidárias. Porém, sem ignorar os processos de invasão cultural e de alienação que também constituem estas culturas, e como forma de evitar o populismo epistemológico segundo o qual estas culturas e sabedorias não devem ser modificadas, estimulamos, ao contrário, um processo pedagógico dialógico, intercultural, baseado numa ecologia de saberes, que mutuamente contribua para o reposicionamento crítico das sabedorias ancestrais e dos conhecimentos científicos (pós/trans)modernos.

\section{Notas}

1 Para aprofundamento da relação entre as obras destes educadores populares e o pensamento decolonial, remetemos o leitor ao nosso livro "Por uma Pedagogia Decolonial na América Latina: reflexões em torno do pensamento de Paulo Freire e Orlando Fals Borda" (MOTA NETO, 2016).

2 Restrepo e Rojas (2010) reforçam as diferenças entre os conceitos de descolonização (a primeira descolonização, nos termos de Castro-Gómez e Grosfoguel) e decolonialidade. Por descolonização se indica um processo de superação do colonialismo, geralmente associado às lutas anticoloniais no contexto de estados concretos, ao passo que decolonialidade se refere ao processo que busca transcender historicamente a colonialidade, 
isso é, subverter o padrão de poder colonial, que permaneceu mesmo após o fim da situação colonial.

3 De forma mais abrangente, Carneiro (1959) afirma que os negros da Costa da Mina aportaram no Brasil a partir do século XVIII, e podem ser divididos em negros do litoral - nagôs, jejes, fantis e axantis, gás e txis (minas) - e do interior, do Sudão islamizado - hauçás, kanúris, tapas, grúncis, e novamente fulas e mandingas.

4 Terecô ou Linha da Mata é "Denominação dada à religião afro-brasileira tradicional de Codó [...] É também conhecido por 'Encantaria de Barba Soêra' ou Bárbara Soeira (entidade sincretizada com Santa Bárbara" e por Tambor da Mata, ou simplesmente Mata (em alusão à sua origem rural ou para diferençá-lo da Mina surgida na capital" (FERRETTI, 1998, p. 05).

5 Entidade espiritual genericamente chamada de caboclo, podendo também designar, no Tambor de Mina, os voduns e os orixás, divindades dessa religião. Para Eduardo Galvão (1976, p. 66), referindo-se à Amazônia, o conceito de encantado "é definido localmente como uma força mágica atribuída aos sobrenaturais. Seres humanos, animais, objetos podem ficar encantados por influência de um sobrenatural. $\mathrm{O}$ conceito não se aplica aos santos ou divindades cristãs".

\section{Referências}

ANDRÉ, M. D.A. Etnografia da Prática Escolar. 12ed. Campinas: Papirus, 2005.

CANDAU, V. M.; KOFF, A. Maria N. S. e. Conversas com...sobre a didática e a perspectiva multi/intercultural. Educação \& Sociedade, Campinas, v. 27, n. 95, maio/ago. 2006, p. 471-493.

CARNEIRO, E. Os cultos de origem africana no Brasil. Rio de Janeiro: Ministério da Educação e Cultura; Biblioteca Nacional, 1959.

CASTRO-GÓMEZ; S.; GROSFOGUEL, R. Prólogo. Giro decolonial, teoría crítica y pensamiento heterárquico. In: CASTRO-GÓMEZ, S.; GROSFOGUEL, R. (Orgs.). El Giro Decolonial: Reflexiones para una diversidad epistémica más allá del capitalismo global. Bogotá: Siglo del Hombre Editores; Universidad Central, Instituto de Estudios Sociales Contemporáneos, Pontificia Universidad
Javeriana, Instituto Pensar, 2007.

DÍAZ, C. J. Hacia una pedagogía en clave decolonial: entre aperturas, búsquedas y posibilidades. Tabula Rasa, n. 13, julio-diciembre, 2010, p. 217-233.

FERRETTI, M. Terecô, a linha de Codó. Anais da VIII Jornada sobre Alternativas Religiosas na América Latina. São Paulo, 1998.

FERRETTI, S. Tambor de Mina. Atlas AfroBrasileiro. Rio de Janeiro: Fase, 2000.

FIGUEIREDO, N. Os "bichos" que curam: os animais e a medicina de "folk" em Belém do Pará. Boletim do Museu Paraense Emílio Goeldi Antropologia. Belém, vol. 10, n. 1, 1994, p. 75-91.

FLEURI, R. M. Desafios à Educação Intercultural no Brasil. Educação, Sociedade \& Cultura, n. 16, 2001, p. 45-62.

GALVÃO, E. Santos e Visagens: um estudo da vida religiosa de Itá, Amazonas. São Paulo: Nacional, 1976.

GRUZINSKI, S. A Colonização do Imaginário: sociedades indígenas e ocidentalização no México espanhol - séculos XVI-XVIII. São Paulo: Companhia das Letras, 2003.

$O$ pensamento mestiço. São

Paulo: Companhia das Letras, 2001.

LE GOFF, Jacques. História e Memória. 2ed. Campinas: Editora da UNICAMP, 1992.

MALDONADO-TORRES, N. La descolonización y el giro des-colonial. Tabula Rasa, n. 9, juliodiciembre, 2008, p. 61-72.

. Sobre la colonialidad del ser: contribuciones al desarrollo de un concepto. In: CASTRO-GÓMEZ, S.; GROSFOGUEL, R. (Orgs.). El Giro Decolonial: Reflexiones para una diversidad epistémica más allá del capitalismo global. Bogotá: Siglo del Hombre Editores; Universidad Central, Instituto de Estudios Sociales Contemporáneos, Pontificia Universidad Javeriana, Instituto Pensar, 2007.

MIGNOLO, W. El Pensamiento Decolonial: 
Desprendimiento y Apertura. Un manifesto. In: CASTRO-GÓMEZ, S.; GROSFOGUEL, R. (Orgs.). El Giro Decolonial: Reflexiones para una diversidad epistémica más allá del capitalismo global. Bogotá: Siglo del Hombre Editores; Universidad Central, Instituto de Estudios Sociales Contemporáneos, Pontificia Universidad Javeriana, Instituto Pensar, 2007.

MOTTA, R. Le Métissage des Dieux dans les Religions Afro-Brésilienne. Religiologiques. Montréal, v. 8, 1993, p. 17-34.

MOTA NETO, J. C. da. A Educação no Cotidiano do Terreiro: Saberes e Práticas Culturais do Tambor de Mina na Amazônia. 2008. 193f. Dissertação (Mestrado em Educação) - Universidade do Estado do Pará, Belém, 2008.

Por uma Pedagogia Decolonial na América Latina: reflexões em torno do pensamento de Paulo Freire e Orlando Fals Borda. Curitiba: CRV, 2016.

OLIVEIRA, D. E. de. Cosmovisão Africana no Brasil - elementos para uma filosofia afrodescendente. Fortaleza: LCR, 2003.

PORTO-GONÇALVES, C. W. Apresentação da edição em português. In: LANDER, E. (Org.). A colonialidade do saber: Eurocentrismo e ciências sociais. Perspectivas latino-americanas. Buenos Aires: CLACSO, 2005.

RESTREPO, E.; ROJAS, A. Inflexión decolonial: fuentes, conceptos y cuestionamientos. Popayán: Universidad del Cauca, 2010.

SALLES, V. Cachaça, Pena e Maracá. Brasil Açucareiro. Rio de Janeiro, 37 (2), 1969, p. 46-55.

SANTOS, B. de S. A gramática do tempo: para uma nova cultura política. São Paulo: Cortez, 2006.

A crítica da razão indolente: contra o desperdício da experiência. São Paulo: Cortez, 2002.

; MENESES, M. P. (Orgs.). Epistemologias do Sul. São Paulo: Cortez, 2010.

TRAMONTE, C. Práticas de Educação Intercultural e Comunitária das Religiões Afro-Brasileiras em Santa Catarina. Os Urbanitas. Ano 1, vol. 1, $\mathrm{n}^{\circ}$. 1, maio/junho, 2004.

WALSH, C. Interculturalidade, crítica e pedagogia decolonial: in-surgir, re-existir e re-viver. In: CANDAU, V. M. (Org.). Educação intercultural na América Latina: entre concepções, tensões e propostas. Rio de Janeiro: 7 Letras, 2009.

\section{Sobre o autor}

João Colares da Mota Neto: Professor da Universidade do Estado do Pará (UEPA). Doutor em Educação pela Universidade Federal do Pará (UFPA), tendo realizado Doutorado Sanduíche na Universidad Pedagógica Nacional de Colombia. Mestre em Educação e Licenciado em Pedagogia pela UEPA. Pesquisador vinculado aos grupos "Núcleo de Educação Popular Paulo Freire" e "Grupo de Estudo Religiões de Matriz Africana na Amazônia", na UEPA, e "José Veríssimo e o Pensamento Educacional Latino-Americano", na UFPA.

Recebido em junho de 2015.

Aprovado em junho de 2016. 